\title{
Factors affecting souvenir purchase behavior: valuable insight for tourism marketers and industry
}

\author{
Meitiana Meitiana \\ Margono Setiawan \\ Fatchur Rohman \\ Dodi W. Irawanto
}

Faculty of Economics and Business

Universitas Brawijaya, Malang, Indonesia

Keywords

Theory of Planned Behavior, attitude, buying intention, purchase behaviour, souvenir

\begin{abstract}
This study aims to identify the factors that influence decision making on souvenirs by using the Theory of Planned Behavior. The approach used in the research method is quantitative approach, and the sample determination used convenience sampling type employing 150 souvenir buyers as research samples in Palangka Raya, Indonesia. The relationship between the variables proposed in the study is tested empirically using Partial Least Square (PLS). This research reflects the consumer's picture of the attitude, intentions, and buying behavior of souvenirs. The results showed that the attitude toward authenticity and attitude toward aesthetics, except attitude toward care and carriage, had a significant effect on the purchasing intention which then will be realized in a real buying behavior. The stronger the intention of someone to buy souvenirs, the greater the souvenir buying behavior will be shown. The results of this study are expected to provide valuable insights for marketers and the tourism industry in formulating and implementing strategies to encourage consumers to purchase souvenirs.
\end{abstract}

Corresponding author: Meitiana Margono Setiawan

Email addresses for the corresponding author: metiana.unibraw@gmail.com

First submission received: $12^{\text {th }}$ May 2018

Revised submission received: 31 ${ }^{\text {st }}$ August 2018

Accepted: $15^{\text {th }}$ October 2018

\section{Introduction}

The handicraft industry becomes one of the significant sources of income for a country because it is widely consumed both locally and internationally. Indonesia has a handicraft industry whose contribution to the country's economy is significant. The handicraft industry is the creative industry subsector that has the greatest contribution to export value, as well as the second largest for household consumption value. In terms of exports, demand for Indonesian handicraft products abroad continues to increase at the average of 11.85 percent per year. The export value contributed 18.26 percent to the export of the creative economy sector, and 1.04 percent of the total exports of Indonesia (Qlapa, 2015; Budiharseno, 2017). In some developing countries, the handicraft sector is being developed to meet the tourism market. This strategy not only aims to increase economic income for local people but also to preserve and revive traditional culture (Cohen, 1993).

Handicrafts become souvenir items are very unique and interesting in Indonesia, especially the city of Palangkaraya. Cultural products made from rattan, textiles, sap nyatu and natural stone jewelry made by local craftsmen can be used as interesting products. Souvenir products can represent and convey the economic, social, and cultural values of the local culture and can lead to the development of products that can satisfy the tourists' desire to make souvenirs as a memento (Klamer, 2003; Wilkins, 2011). Besides, craft products as souvenirs can have a competitive advantage (Pugh and Wood, 2004). Empirical results indicate that attitudes toward other cultures can help to predict the intent of purchasing products (Cai and Shannon, 2012) including souvenir products (Kim \& Littrell, 1999; Yu \& Littrell, 2003) and cultural products (Cho \& Lee, 2013). Although much research has been done on souvenir topics and souvenir types purchased, more research is still needed on shopping and purchasing souvenirs in tourism (Lehto,

www.jbrmr.com A Journal of the Academy of Business and Retail Management (ABRM) 
Cai, O'Leary, \& Huan, 2004), and the need to extend research to other countries, especially non- west (Wilkins, 2011). Some research on souvenirs has been successfully used to predict behavioral intentions (Cho and Lee, 2013, Yu and Littrell, 2003; Lee, Kim, Seock \& Cho, 2009; Hu and Yu, 2007). However, no research has been found in the empirical studies model above to predict buying behavior.

Some previous research on Theory of Planned Behavior proved able to predict and explain consumer behavior (Stancu et al., 2016; Giampietri, Verneau, Del Giudice, Carfora \& Finco, 2018; Ma, Hipel, Hanson, Cai \& Liu, 2018). Although Fishbein and Ajzen (1975) assume that the buying behavior is determined by, and predicted from, the intentions of individual behavior, yet further studies show that intentions have no effect on consumer behavior (Deng, 2015; Kothe and Mullan, 2014). In relation to that, the current research seeks to expand research on souvenirs in the city of Palangka Raya by using the Theory of Planned Behavior model. Research on souvenirs provides valuable implications for the tourism industry. Marketers and retailers in the souvenir industry can determine their consumer segment based on the variables identified in the current study and develop more appropriate product attributes. In addition, research on souvenirs will contribute from a strategic aspect as cultural products are expected to reach wider overseas markets (Cho and Lee, 2013).

\section{Literature Review}

\subsection{Attitude}

Positive tourism activities are influenced by the attitude of tourists about the authenticity (attitude toward authenticity) craft and about the features of handicraft products (Yu \& Littrell, 2003). Attitudes toward authenticity have a significant effect on purchasing intentions (Cho and Lee, 2013). The consumer attitudes toward souvenirs reflect their perceptions of important and valuable product attributes Attributes related to physical characteristics, cultural peculiarities, and its use. When tourists visit important places that have social, historical, and cultural elements, they expand their search for the authenticity and aesthetics of craft souvenirs (Littrell, 1996).

Attitudes towards aesthetic (attitude toward aesthetic) souvenirs have a strong positive effect on purchasing intentions (Kim and Littrell, 1999). A more favorable tourist attitude towards the aesthetic aspect of souvenirs tends to lead to strong buying intentions. Similarly, Korean respondents tend to have a positive attitude towards the intention of purchasing cultural products. Attitudes towards aesthetic (attitude toward aesthetic) cultural products have a significant effect on purchasing intentions (Cho and Lee, 2013). Respondent's evaluation of aesthetics became an important variable in Korean cultural products (Lee et al., 2009).

Lee et al. (2009) conducted a study on the attitude of American, Korean, and Chinese female consumers to the purchase intentions of Korean textiles and products related to clothing. The results of their study found that attitudes toward the ease of care and carriage of cultural products such as T-shirts, scarves, handheld accessories, and leather products were significantly correlated with intention and purchase intentions. Attribute souvenirs that are easy to carry and pack (attitude toward care and carriage) during the trip should not be ignored because these attributes are considered important by tourists (Mogindol and Bagul, 2016). Kim and Littrell (2001) assert that attitudes toward foreign cultures are significant variables affecting souvenir purchase intentions.

Based on the theoretical and empirical studies above, the hypotheses proposed in this study are as follows:

Hypothesis 1: Attitude toward authenticity has a significant and positive effect on buying intention. Hypothesis 2: There is a significant and positive effect of attitude toward aesthetics on the intention. Hypothesis 3: Attitude toward care and carriage has a significant and positive effect on the intention.

\subsection{Buying Intention and Purchase Behavior}

Behavioral intent signifies a plan and a determination to perform a targeted behavior. In general, the individual's intention to perform certain behaviors grows stronger according to the positive attitudes toward behavior. The stronger a person intends to perform the behavior, the more likely the behavior will be done (Ajzen, 1991; Lee, 2016). Understanding consumer's purchase intentions is very important because their final buying behavior can be predicted from their intentions. Consumers decide whether they intend to continue with a purchase based on information available to them (Pappas, 2016). Purchase behavior is determined and estimated from the intentions of individual behaviors. The stronger the 
purchase intentions on souvenirs is expected to increase purchasing behaviors (Stancu et al 2016, Giampietri et al., 2018, Ma et al., 2018). Based on the theoretical and empirical studies above, the hypothesis proposed in this study is as follows:

Hypothesis 4: Buying intention has a significant and positive effect on purchasing behaviors.

\section{Research Methods}

\subsection{Research Design and Sampling}

The approach used in the research method is quantitative approach, and the sample determination used convenience sampling type employing 150 souvenir buyers as research samples in Palangka Raya, Indonesia. A total of 121 questionnaires were returned to the researcher (return rate $80.67 \%$ ). At the tabulation stage, a total of 21 questionnaires could not be continued in further statistical analysis, due to incomplete answers, or outlier data

\subsection{Data Collection}

The questionnaire is designed to measure all latent variables. Collecting data with questionnaires is done by meeting respondents in souvenir outlets and distributing questionnaires to respondents to fill in as directed. The selection of samples in this study is done using the type of convenience sampling, the person who by chance were found shopping souvenirs when the researchers conducted the research (Sekaran \& Bougie, 2016). Souvenir buyers who become research samples are those who are shopping and those who have finished buying and are willing to fill in the respondents' questionnaires.

\subsection{Measurement technique}

The five-point Likert scale with scores ranging from 1 (strongly disagree) to 5 (strongly agree) is used for all latent variables. Respondents were asked to show their responses to a series of statements relating to each latent variable. Data collection is done by using questionnaires, so that the seriousness of respondents in answering questions or statements is very important in the study. The validity of a research result is determined by the measuring instrument using two tests, namely validity testing and reliability testing.

\subsection{Data analysis method}

The relationship between the variables proposed in the study is tested empirically using Partial Least Square (PLS). The population of this research is all souvenir buyers. A total of 150 questionnaires were circulated, out of which returned 121 questionnaires, and as many as 100 questionnaires could be used in the statistical analysis. A sample size of 100 people in Partial Least Square (PLS) is considered adequate (Hair et al., 2014).

\section{Results and Discussion}

\subsection{Characteristics of Respondents}

The demographic characteristics of the respondents showed that the number of male respondents was $28 \%$ while $72 \%$ of the respondents were women. The age groups of the respondents consisted of those under 25 years old (16\%), between 25 and 55 years (78\%) and the remaining 6\% was the classified in above 55 -year-old age group. The majority of respondents received a bachelor's degree (52\%), followed by postgraduate (32\%) and high school diploma (16\%). 84\% of the respondents hail from Indonesia were $84 \%$ and 16\% hail from outside Indonesia (Japan, Australia, Netherlands, and Germany)

Table 1. Respondents' Characteristics

\begin{tabular}{|l|l|l|l|}
\hline Classification & Type & Amount & Percentage \\
\hline Gender & Male & 28 & $28 \%$ \\
\hline & Female & 72 & $72 \%$ \\
\hline Age (years old) & $<25$ & 16 & $16 \%$ \\
\hline & $25-55$ & 78 & $78 \%$ \\
\hline & $>55$ & 6 & $6 \%$ \\
\hline Education & High School & 16 & $16 \%$ \\
\hline & Bachelor & 52 & $52 \%$ \\
\hline & Postgraduate & 32 & $32 \%$ \\
\hline Citizenship & Indonesian & 84 & $84 \%$ \\
\hline & Non-Indonesian & 16 & $16 \%$ \\
\hline
\end{tabular}




\subsection{Test of Measurement}

As shown in Table 1, the outer loading values for each indicator of the Attitude toward Authenticity variable, Attitude toward Aesthetics, intent and purchase behavior has met a convergent validity due to the T-Statistic value above 1.96 and the outer loading value at above 0.5 (Chin et al., 1998). Composite Reliability ranges from 0.720 to 0.874 , since values have met above 0.7 (Hair et al., 2014), the measurement model shows an acceptable reliability. The AVE value of each variable also meets the required validity because the value is greater than 0.5 . The AVE root of each variable is higher than the correlation between variables and other variables indicating that the model has enough discriminant validity (Hair et al., 2014).

Table 2. Summary results for model testing

\begin{tabular}{|l|l|l|l|l|}
\hline Variable & AVE & $\begin{array}{l}\text { Composite } \\
\text { Reliability }\end{array}$ & Outer Loadings & $\mathrm{R}^{2}$ \\
\hline Attitude toward Authenticity & 0.581 & 0.874 & $0.751-0.797$ & \\
Attitude toward Aesthetics & 0.535 & 0.744 & $0.563-0.676$ & \\
Buying Intention & 0.550 & 0.859 & $0.690-0.767$ & 0.509 \\
Purchase Behaviors & 0.521 & 0.815 & $0.549-0.760$ & 0.372 \\
\hline
\end{tabular}

\subsection{Structural Model}

Structural model testing is shown from the R-square value of the equation between the latent variables. The Effect of Intention on Purchase Behavior gives an R-square value of 0.372 which can be interpreted that variability of Purchase Behavior can be explained by the variability of Intention of 37.2\%, while $62.8 \%$ explained by another variable is not examined. Furthermore, hypothesis testing is done by using $t$ test on each lane of influence between dependent variable and independent variable. The results of hypothesis testing are shown in Table 3.

Table 3. Hypothesis Test Results

\begin{tabular}{|l|l|l|l|}
\hline Structural Model & Path Coefficient & T-Statistic & Hypothesis \\
\hline Attitude of authenticity $\rightarrow$ Intention & $0.428^{* *}$ & 3.136 & Significant \\
\hline Attitude of aesthetics $\rightarrow$ Intention & $0.317^{* *}$ & 2.018 & Significant \\
\hline Attitude of Care \& Carriage $\rightarrow$ Intention & $(0.067)$ & 0.525 & Insignificant \\
\hline Intention $\rightarrow$ Purchase Behavior & $0.610^{* *}$ & 10.297 & Significant \\
\hline
\end{tabular}

The results of hypothesis testing resulted in support for hypothesis 1 and hypothesis 2, namely attitudes toward Authenticity and Attitude toward Aesthetics have positive effect on consumers of souvenirs so they increase the intention of purchasing souvenirs. These findings support other studies (Cho and Lee, 2013; Yu and Littrell, 2003) who found that Attitude toward Authenticity and Attitude toward Aesthetics had a significant effect on purchase intentions.

However, the test results do not support hypothesis 3 which states that attitude toward care and carriage affects the intention. This means that the attitude toward care and carriage has not been statistically proven to be able to affect customers' buying intention on souvenir products. The results of further testing support hypothesis 4 which states the intention to influence the buying behavior of souvenirs. This shows that the bigger the consumers' intent in souvenir products the more it improves their behavior in making souvenir purchases. 


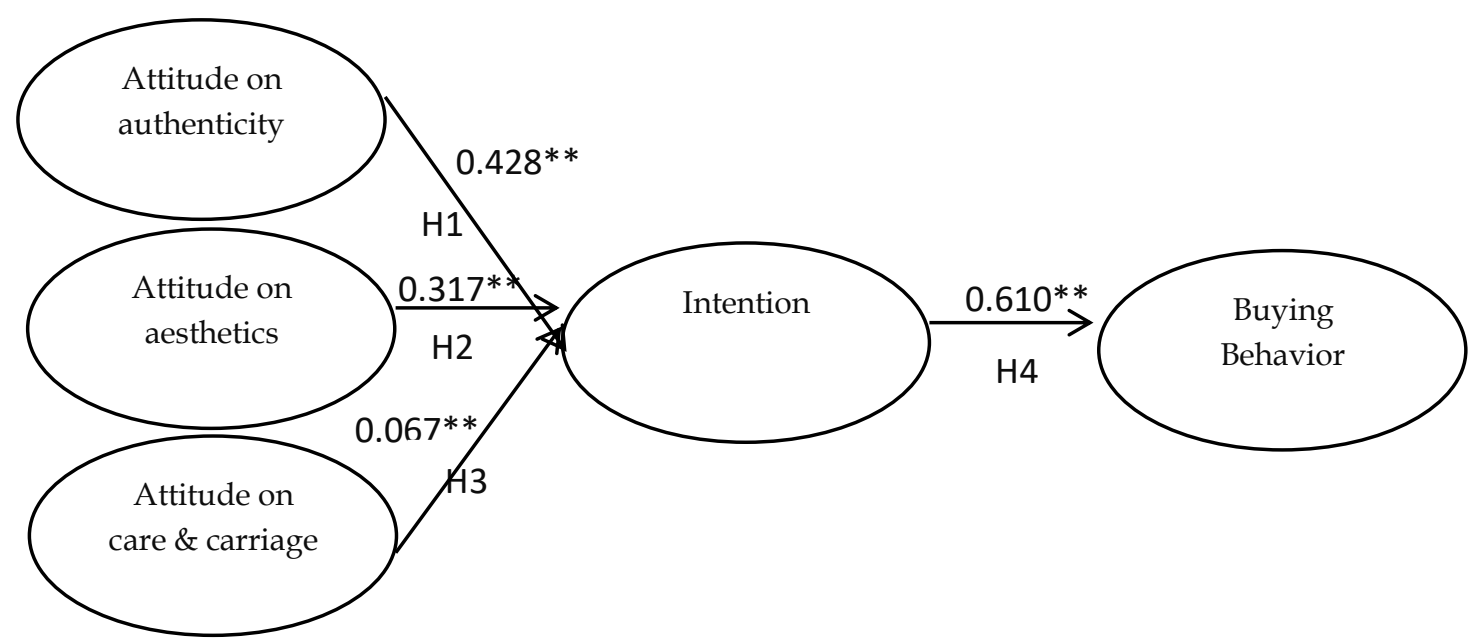

Fig 1. Full Structural Model

\section{Discussion}

The results highlight the effect of consumers' attitude toward authenticity and attitude toward aesthetics on the buying intention. Attitudes towards the authenticity and aesthetics of cultural products have a significant effect on purchase intentions. The authenticity attributes are highly rated by the tourists who buy local handicraft products (Mogindol \& Bagul, 2016). Consumer confidence about the features of craft products has a positive effect on spending attitudes that will ultimately affect purchasing intentions (Yu \& Littrell, 2003). Local handmade cultural souvenirs are said to be an important ingredient in building authenticity (Asplet \& Cooper, 2000), especially if intended to describe a culture-based design. Tourists are more willing to buy souvenirs if the displays are high quality, imaginative, and attractive. When consumers make souvenir purchases, the products they consider to be important are souvenirs that reflect local culture as it can serve as a means of storing memories and will remind them of the area where souvenirs are purchased (Swanson \& Horridge, 2006) as well as concrete evidence of their travel experiences (Wilkins, 2011), as they may feel the need to bring home something tangible to concretize and preserve their memories of the journey (Gordon, 1986). The beauty and uniqueness of local souvenirs can evoke memories of products and places where tourists buy them.

Tourist attitudes towards aesthetic qualities of souvenirs are the best predictors of their purchase intentions (Kim \& Littrell, 1999). Tourists with a more favorable attitude towards the aesthetic aspect of souvenirs tend to have strong purchase intentions. Attitudes attracting tourists to other cultures can affect their travel experiences including souvenir purchase intentions (Kim and Littrell, 2001). Swanson and Horridge (2006) suggest that tourism motivation affects product attributes that include aesthetics and uniqueness. Aesthetic attributes are described as "interesting designs and colors" and "items that can be worn or displayed at home", unique attributes described as "new, innovative, intelligent, or made by famous craftsmen from the region". Product-oriented tourists will buy products focusing on craftsmanship and aesthetic quality, while on the contrary, process-oriented travelers focus on creating cultural relationships and craftsmen through interaction with local handicraft producers and sellers, watch craft demonstrations, and learn about historical and cultural contexts for crafts (Yu and Littrell, 2003).

The research result on insignificicant effect of attitude toward care and carriage on the intention supports the findings of Kim and Littrell's (1999) research and of Cho and Lee's (2013) study who conclude that attitudes on ease of care and transport of souvenirs have no effect on the intention of souvenir purchase. This finding is likely because most souvenirs purchased by consumers are souvenirs of small size or lightness, making it easier to carry and maintain than those made from other materials. The results of this study are not in line with research conducted by Lee et al. (2009), that attitudes on ease of care and carrying souvenir products are significantly correlated with intention and purchase intentions. Souvenir attributes that are easy to pack or take during a trip should not be overlooked as these attributes are highly rated by tourists who buy local handicraft products (Mogindol and Bagul, 2016). When 
travelers travel far and use airplanes, the size, fragility, and care of the product becomes an important attribute to consider. These findings support the research conducted by Stancu et al. (2016), Giampietri et al. (2018), and Ma et al. (2018) who find that intentions have an effect on purchasing behavior. But it is not in line with the research conducted by Deng (2015), Kothe and Mullan (2014). The effect of high purchasing intent on shopping behavior indicates that intention is a predictor of actual actual behavior.

The findings show that the buying intention is more likely able to influence the buying behavior of souvenirs. These findings support research conducted by Stancu et al. (2016), Giampietri et al. (2018), and Ma et al. (2018) who find that intentions have an effect on the purchasing behavior. The stronger the purchase intentions on souvenirs, the greater increase in purchasing behavior is expected (Kim and Littrell (1999); the stronger the consumer intention to shop, the more likely they will often visit the mall and spend more money during their mall visit (Cai and Shannon, 2012). The effect of high purchasing intentions on spending behavior indicates that intention is a predictor of actual behavior. However, these results are not in line with research conducted by Deng (2015), and Sanyal (2014). Intention does not always have a positive effect on the actual use of a product (Nugroho, Bakar \& Ali, 2017). When Indian consumers talk about uniqueness, exclusivity and personal taste, the majority of the market is still far from this perception and the brand value that greatly influences the use of luxury goods. The Indian consumer mindset is still that of an 'aspirer' rather than 'connoisseur'. The results of Sanyal's (2014) study show that in the Indian market environment, customers are more concerned with subjective norms than their own attitude while they have the intention to purchase luxury goods. The Indian culture is more or less a collective culture. As a whole, Asian collectivist consumers (India) are involved in less impulsive purchases than Western individualist consumers, despite a highly developed shopping culture in Asia. Deng (2015), Wahyuni and Ginting (2017) shows that consumers still pay more attention to quality, product prices, shopping convenience, shopping goals, and social pressures. His research shows that in changing intentions into behaviors, individual characteristics and situational factors work together to influence consumer decision making.

\section{Managerial and Theoretical Implications}

The theoretical implication of this finding is that to identify consumer intentions in buying souvenirs, attitudes should include two-dimensional measurements of attitude toward aesthetics and attitude toward authenticity. Furthermore, to conduct the buying behavior of cultural product souvenirs, consumer's positive attitude should be formed more strongly in order to generate consumer buying intention. Understanding consumer purchase intentions is very important because their final buying behavior can be predicted from their intentions.

Marketers need to focus on attitudes to develop buying behavior. To shape attitudes, marketers should focus on all dimensions of attitudes by emphasizing that the resulting souvenir products have satisfied consumer desires both in terms of authenticity and beauty in order to give them a competitive advantage. Promotion emphasizing on cultural aspects needs to be done so that consumers are more interested and not just stop at the intention to buy it but to act out on it and show the actual buying behavior.

\section{Conclusions and Direction for Future Research}

Theory of Planned Behavior has become a very useful framework to predict souvenir buying behaviors. The findings indicate that attitude toward authenticity and attitude toward aesthetics influence the souvenir purchase intention, whereas attitude towards care and carriage is not found to affect customer intention. Furthermore, the intentions affect the buying behavior, which means that the greater intent the consumers of souvenir products have, the more it improves their behavior in making souvenir purchases. These findings indicate that one's intentions are predictions for consumer behavior.

This study has some limitations that can be overcome in further research. The contribution of attitude toward authenticity and attitude toward aesthetics toward intention is $50.9 \%$ and intention toward purchasing behavior is only $37.2 \%$, so there are possibly some other variables that can influence the relationship between attitude to intention and intention to behavior. The literature also suggests that subjective norms and perceived behavior control, as well as demographic factors (eg sex, age, and income) 
contribute to the strength of the relationship between attitudes and behavior. Therefore, future research can use these variables to enrich the study of souvenirs and can improve predictions of buying behavior.

Other limitations, the lack of control of the researcher in the process of filling in the questionnaire can cause the question to be misinterpreted by the respondents who could potentially create a validity problem. When respondents sometimes provide unexpected answers or responses, the sample data will not be fully representative of the population. To overcome these problems, researchers can work well with respondents, so that attitudes and behavior can be measured accurately.

\section{Reference}

Ajzen, I. (1991). The theory of planned behavior. Organizational behavior and human decision processes, 50(2), 179-211.

Asplet, M., \& Cooper, M. (2000). Cultural designs in New Zealand souvenir clothing: the question of authenticity. Tourism Management, 21(3), 307-312.

Budiharseno, R. S. (2017). Factors affecting online buying behavior on g-market site among international students in Busan: A qualitative research. Arthatama: Journal of Business Management and Accounting, 1(1), 1-5.

Cai, Y., \& Shannon, R. (2012). Personal values and mall shopping behavior: The mediating role of attitude and intention among Chinese and Thai consumers. Australasian Marketing Journal (AMJ), 20(1), 37-47.

Chin, W. W. (1998). The partial least squares approach to structural equation modeling. Modern methods for business research, 295(2), 295-336.

Cho, Y., \& Lee, Y. (2013). Analysis of Factors Affecting Purchase Intentions for Fashion Cultural Products. Journal of the Korean Society of Clothing and Textiles, 37(1), 101-112.

Cohen, E. (1993). The study of touristic images of native people: Mitigating the stereotype of a stereotype, In D. Pearce, \& R. Butler (Eds), Tourism research: Critiques and challenges, pp. 36-69. London: Routledge.

Deng, X. (2015). Understanding Chinese consumers' ethical purchasing decision-making process: A combination of qualitative and quantitative study. Geoforum, 67, 204-213.

Fishbein, M., \& Ajzen, I. (1975). Belief, Attitude, Intention, and Behavior: An Introduction to Theory and Research. Reading, MA: Addison-Wesley.

Giampietri, E., Verneau, F., Del Giudice, T., Carfora, V., \& Finco, A. (2018). A Theory of Planned behaviour perspective for investigating the role of trust in consumer purchasing decision related to short food supply chains. Food Quality and Preference, 64, 160-166.

Gordon, B. (1986). The souvenir: Messenger of the extraordinary. The Journal of Popular Culture, 20(3), 135-146.

Hair, J. F., Gabriel, M., \& Patel, V. (2014). AMOS covariance-based structural equation modeling (CB-SEM): Guidelines on its application as a marketing research tool. Brazilian Journal of Marketing, 13(2).

$\mathrm{Hu}$, B., \& Yu, H. (2007). Segmentation by craft selection criteria and shopping involvement. Tourism Management, 28(4), 1079-1092.

Kim, S., \& Littrell, M. A. (1999). Predicting souvenir purchase intentions. Journal of Travel Research, 38(2), 153-162.

Kim, S., \& Littrell, M. A. (2001). Souvenir buying intentions for self versus others. Annals of tourism research, 28(3), 638657.

Klamer, A. (2003). Social, cultural and economic values of cultural goods. Cultural Economics, 3(3), 17-39.

Kothe, E. J., \& Mullan, B. A. (2014). A randomised controlled trial of a theory of planned behaviour to increase fruit and vegetable consumption. Fresh Facts. Appetite, 78, 68-75.

Lee, Y., Kim, S., Seock, Y. K., \& Cho, Y. (2009). Tourists' attitudes towards textiles and apparel-related cultural products: A cross-cultural marketing study. Tourism Management, 30(5), 724-732.

Lehto, X. Y., Cai, L. A., O'Leary, J. T., \& Huan, T. C. (2004). Tourist shopping preferences and expenditure behaviours: The case of the Taiwanese outbound market. Journal of Vacation Marketing, 10(4), 320-332.

Littrell, M. A. (1996). Shopping experiences and marketing of culture to tourists. Tourism and culture: Image, identity and marketing, 107-20.

Ma, J., Hipel, K. W., Hanson, M. L., Cai, X., \& Liu, Y. (2018). An analysis of influencing factors on municipal solid waste source-separated collection behavior in Guilin, China by Using the Theory of Planned Behavior. Sustainable cities and society, 37, 336-343.

Mogindol, S. H., \& Bagul, A. H. B. B. P. (2016). Tourists' Perceptions about an Appealing Handicraft. Tourism, Leisure and Global Change, 1(1), 10-24.

Nugroho, A. H., Bakar, A., \& Ali, A. (2017). Analysis of technology acceptance model: Case study of Traveloka. Arthatama: Journal of Business Management and Accounting, 1(1).

Pappas, N. (2016). Marketing strategies, perceived risks, and consumer trust in online buying behaviour. Journal of Retailing and Consumer Services, 29, 92-103.

Pugh, C., \& Wood, E. H. (2004). The strategic use of events within local government: A study of London Borough Councils. Event Management, 9(1-2), 61-71. 
Qlapa. (2015). Potensi Industri Kerajinan Tangan Indonesia (Potential of Indonesian Handicraft Industry). Retrieved from https:// qlapa.com/blog/potensi-industri-kerajinan-tangan-indonesia.

Sanyal, S. N., Datta, S. K., \& Banerjee, A. K. (2014). Attitude of Indian consumers towards luxury brand purchase: an application of 'attitude scale to luxury items'. International Journal of Indian Culture and Business Management 5, 9(3), 316-339.

Sekaran, U., \& Bougie, R. (2016). Research methods for business: A skill building approach. John Wiley \& Sons.

Stancu, V., Haugaard, P., \& Lähteenmäki, L. (2016). Determinants of consumer food waste behaviour: Two routes to food waste. Appetite, 96, 7-17.

Swanson, K. K., \& Horridge, P. E. (2006). Travel motivations as souvenir purchase indicators. Tourism management, 27(4), 671-683.

Wahyuni, S., \& Ginting, M. (2017). The impact of product quality, price and distribution on purchasing decision on the Astra motor products in Jakarta. Arthatama: Journal of Business Management and Accounting, 1(1), 18.

Wilkins, H. (2011). Souvenirs: What and why we buy. Journal of Travel Research, 50(3), 239-247.

Yu, H., \& Littrell, M. A. (2003). Product and process orientations to tourism shopping. Journal of Travel Research, 42(2), $140-150$. 